\title{
Self-care and sense of life in elderly adults who have diabetes mellitus in Tumbes hospital
}

\begin{abstract}
This is a case study, aimed at unveiling the self-care and sense of life in older adults suffering from diabetes mellitus who go to a hospital in Tumbes-2015. Method; Qualitative research with a case study approach; The sample was 10 Adults when the interviews conducted did not produce any authentically new information. The results were the categories: Losing the meaning of life, Finding motivations in Life, Thinking and sharing with the family, Demonstrating self-care practices and Perceiving death close. In conclusion, according to older adults, old age cannot be isolated from the continuous development of each person, from how he lived the previous stages of his life and above all facing a chronic illness that makes them increasingly dependent, useless without responsibilities and motivations to move forward.
\end{abstract}

Keywords: self care, sense of life, the elderly, diabetes mellitus
Volume 3 Issue 2 - 2019

\author{
Lilia Jannet Saldarriaga Sandoval,' Edilma \\ Casimiro Gomes Serafim² \\ 'Professor, Intensive Care Specialist, National University of \\ Tumbes, Peru \\ ${ }^{2}$ Nurse, Specialist in Intensive Care, Heart Hospital Alberto \\ Studart Gomes, Peru \\ Correspondence: Lilia Jannet Saldarriaga Sandoval, Magister \\ em Ciencias en Enfermeria, Docente Universidad Nacional de \\ Tumbes- Especialista Hospital Regional, Lambayeque, Peru, \\ Email liyasa45@hotmail.com
}

Received: August 22, 2018 | Published: March 22, 2019

\section{Introduction}

According to certain authors ${ }^{1}$ as the population ages, the presence of chronic and disabling diseases increases ${ }^{2}$ one of them diabetes mellitus; however, the growing longevity has its own requirements that cannot be ignored and it must be ensured that it is necessary to compensate with quality of life that supposes to be an older adult.

The older adult ${ }^{1}$ is a person who has passed 65 years of age, and who often has a multipathology including diabetes mellitus, usually, diseases diagnosed in older adults in the city of Tumbes are not treated properly and opportunely, tend to cause complications and consequences that hinder the independence and autonomy of people and family.

In Peru, according to the Ministry of Health ${ }^{3}$ the population is $27,595,462$, in Tumbes with a population of 204, 207, and adult population greater than 6,819 inhabitants, representing $6.70 \%$ of the total population of Tumbes; in the region, the average lifespan of the population has experienced a significant gain and for the period 2010 - 2015 it has been estimated at 72.7 years, the life expectancy at birth of the Tumbes region is 1.6 years longer than the estimated life expectancy for the country for the same period. When analyzing the morbidity rate, it is observed that in the stages of life of the older adult they present the highest rates with 25.8 per 1000 inhabitants. It also records that diabetes mellitus in the adult population represents $1.5 \%$ and in the older adult, $4.6 \%$ of incidence by demand in the outpatient clinic, besides representing the thirteenth cause of general mortality due to diabetes with a $2.2 \%$ and mortality in the age group of the adult population $3.5 \%$ and in the elderly $2.5 \%$.

In fact, diabetes mellitus, a chronic disease, that elderly people live in, makes them see that the body begins to deteriorate. This makes them accept or think that everything will continue the same, or the only change in their diet, treatments, and the analysis afflicts them and they only think about dying or living happily as their life was at some point, the direction of their life no longer belongs to them and it happens to belong to their loved ones or requires that selfcare be based on the principle of self-care and respecting oneself, while intensifying the relationship with oneself, constitutes being the subject of one's actions. ${ }^{3}$

The above is observed in hospital medicine and emergency services, where older adults relapse due to complications, with family support and sometimes alone, will be related to the care they have of their illness in their home, as it is that they face it even under the most difficult circumstances to add to its life a deeper meaning, and to preserve its value, its dignity and generosity.

Among the sequels there is no exact record of those produced by diabetes; however, these are the product of illness; It is often related to losses in many areas, call it individually as your health; familiar as divorce or death; in the social like the friends; or work such as dismissals or retirements, which affects the emotional state of the subject, making him reflect on his life and sometimes even wishing to die, for the days that he demands to be in hospital medicine and emergency services. ${ }^{2}$

The reality observed during the care practice, in some circumstances evidence that they find what happened to them unfair and they get angry with themselves and with the people they love, situation and feelings that are part of the beginning of the process of coping with the disease, in addition to taking into account that the act of taking care of each other is the responsibility of each human being, emphasizing the importance of the individual's relationships with himself, ${ }^{4}$ however, that and how to live is a suffering and each person reacts in a different way, which increases the levels of disability and physical dependence with repercussions on the familiar. ${ }^{5}$

Caring is a professional and personal value, it is of vital importance that govern the actions and attitudes in relation to those who take care of themselves, such as older adults with diabetes, whose roles change and are unaware of the routine tests of the disease that he uses equipment, devices that cause fear, in addition to completely disconnecting him from his family habits, experience whose reactions impact his self-perception due to the difficult situation and sometimes suffering due to his illness that requires care that involves the person daily to achieve a harmonious balance in your life. 
The research is justified by the essence of nursing care that is centered on the person in an integral way in all its dimensions; biological, spiritual, social, aesthetic and ethical, with a holistic vision and entails acting effectively and committed, guaranteeing a physical, mental, social and spiritual well-being of the person. After these reflections we formulate the following: What is the self-care and sense of life in older adults with diabetes mellitus in a hospital in Tumbes? Having the objective of; analyze and understand self-care and sense of life in older adults with diabetes mellitus in a hospital in Tumbes.

\section{Materials and methods}

Following the proposed objective, we chose the qualitative paradigm $^{6,7}$ using the Case Study approach, which was developed taking into account the following principles. ${ }^{6}$

An attempt was made to reveal the multiplicity of dimensions present in the elderly who suffer from diabetes, focusing it as a whole, that is, the natural complexity of the situations, evidencing the interrelationships of its components, the self-care and sense of life of older diabetic adults.

The use of multiple sources of information helped to develop converging research lines; the main source of information were the elderly with diabetes, it was sought to portray the depth of reality, as it was to analyze the meaning of life, as subjective aspects inherent to the protagonist object of study, written information of the analysis of the clinical history. Once the key elements and approximate limits of the problem were identified, the necessary information was systematically collected systematically, using the instruments. They tried to bring these divergences of opinions to the study, revealing even their point of view about the situation and revealing a diversity and wealth of human behavior. The situation was Self-care and a sense of life of older adults suffering from diabetes, knowing their experiences in their life, motivations that are different and individual; that is, they vary from person to person, all this allowed conclusions to be drawn.

The population according to the registered income of older adults with diabetes mellitus was 35 women and 31 men in the August to December 2015, period in the medicine and emergency services of Tumbes Hospital. ${ }^{8}$

For the collection of the sample, the saturation of the speeches was used, with 10 participants, that is to say, when the interviews conducted did not produce any authentically new information, the convenience sampling was used to select the informants, Convenience sampling was used to select the informants, they were people whose origin was from the marginal urban zone who are people whose origin they were from the marginal urban zone of Tumbes. whose marital status is married and widowed, of those who work as stevedores, farmers, and are unemployed, are alone with their companions (os), with one of their children or closest family member, of the review of medical records there are hereditary antecedents of Diabetes and risk factors of obesity, illness that exceed five to seven years from the beginning of the diagnosis and whose hospitalizations have been due to the complications of the disease, as well as due to omission in the treatment, excesses in the diet or for other diseases.

It was taken into account as criteria: Inclusion criteria; Older adults hospitalized with diabetes mellitus with more than 2 years of illness, older adults hospitalized with diabetes mellitus without neurological sequels that prevented them from giving the interview, older people who authorized to participate in the study. Inclusion criteria; older adults hospitalized with diabetes mellitus with less than 2 years of disease, older adults hospitalized with diabetes mellitus with neurological sequels that prevented them from giving the interview.

As a technique, we use three techniques: indirect participant observation, semi-structured interview and documentary analysis.

The instrument that guaranteed the obtaining of true, auditable and scientific information is the semi-structured interview guide and the field notebook to record the observations that corroborated the speeches obtained with recording.

He coordinated with the chief of the emergency services and medicine of a Hospital in Tumbes, in order to count on his participation in the investigation.

We proceeded to the reliable transcription of recorded discourses transcribing oral to written word, from the identification of units of meaning through the decontextualization of discourses, large categories emerged as a result of research. The categories were contrasted with the information obtained through observation enriched with the theoretical framework and corroborated by the units of meaning of the speeches as stated by the informants.

In this research, the following ethical principles and scientific rigor, the criteria commonly used to evaluate the scientific quality of a qualitative. ${ }^{9,10}$

\section{Analysis and discussion of results}

Each stage of life gives us opportunities for creative transformations and growth based on the challenges that have to be faced. The old age or stage of integration is one of them; as you cannot predict who will navigate the transitions of life more successfully, you do not have the potential to promote healthy aging.

The older adult in the study, in the life cycle of old age, constitutes a continuous development of each person, that above all facing a chronic disease needs individual and collective skills in their care and makes them reflect on their experiences in the previous stages of life. their life that makes them increasingly dependent and often the disease makes them feel useless because they cannot take responsibility and even lose the motivation to move forward; it is here that if he is not able to assume his self-care, he should have a compensatory self-care helped by his family and by the health personnel, especially the nurse, who should provide holistic care with a holistic vision where the person should be considered as a It is impossible to be fragmented and called by its name not as a "diabetic" but as the person who suffers from diabetes and above all it will help him to live in peace taking conscience of his own life.

\section{Loss of sense of life}

Having clear objectives is the first requirement to draw life projects that consist of achieving the goals, values and ideals that we want to achieve. He who lacks ends for his own life also lacks plans to reach them, consequently he has no task to carry out; this absence of vital projects causes unemployment, lack of tasks felt as one's own, and only work then is a kind of forced obligation, which one is forced to perform without desire, and even against his will. In addition, the absence of projects and tasks experienced as their own generates something that is the ground where the loss of the meaning of life occurs

The meaning of human life implies two aspects; first if it has a reason, that is, if it has an efficient cause if it is intelligible, second if 
it has a for that, a final cause, that is, if it has an end, if it represents a value that interpellates the responsibility inseparably united, otherwise in human life there are two realities that seem to put this intelligibility in crisis, to the point of appearing as contradictory with life itself: death and suffering, which can be physical or moral, requires first of all to overcome it, soften it and, in As far as possible, eliminate it, however, depends on the attitude of the person suffering from chronic diseases, this is variable. ${ }^{11}$

(...)I feel that I am tied to something that I do not want to be tied to and when I am in the hospital they treat me with one and another medication I think it is no longer useful (...)MI

Who has tried to answer the question about why bad things happen to good people, has realized from their own experience that the bad things that happen to us in life have no design when they occur to us. They do not happen for some reason that would make us accept it willingly. But we can give them a meaning, we can redeem them from the absurd by imposing a meaning, reaching a conviction of life. ${ }^{12}$

(..)So that our lives are not as they used to be and with this disease one does not know(..) AI (..)Having to adapt to diabetes has enslaved me, nothing is the same, we have nothing left to do (..)JI

As it is expressed for sick people this dramatically accentuates the situation, since they are considered unproductive and therefore do not count (unless as consumers of expensive medical treatments), they no longer express denial of death in this sense but rather imply the denial of life itself.

(..). When I get sick when I wake up in the morning, everything changes and that makes you tired, in my life and I have a desire to flee (...) RI

The elderly person has lower productivity, do not visualize the generation of ideas and the development of large projects to position themselves socially, the meaning of life, does not allow adequate decisions, their values and attitudes do not show tolerance, but above all not they have clarity of their self-realization as a constant search of their life cycle On several occasions, it is undoubted that the human being finds the meaning of life, in a diversity of positive and enriching cultural, scientific, artistic, sports activities, etc. ${ }^{4}$

\section{Thinking and sharing with the family}

Love is the meaning of life, man is created by love and for love, he can rest when he has fulfilled and performed as he does within the family, in which there are responsibilities such as upbringing, the independence that is given to the older children and then the accompaniment that they do as grandparents to their children and grandchildren, gives meaning in their life in a more personal way, of spiritual growth and of service to others; this obligation that becomes a mission or destiny that they feel they have and want to fulfil, as a process within their life.

(...)Conclude with the upbringing ", task that ends when the children leave the house to form their own families (...) JI (...) We have always tried to be together as a family, I have raised my children with a lot of effort and we have learned to educate them all are professionals (...) AI (...) First are the children and the responsibilities we have to conclude with the upbringing(...) PII

It can be affirmed that older adults have been active and occupied, interacting with those around them, they have acquired achievements in the past, they have had a positive vision of themselves through concrete actions to achieve the satisfaction they seek to value and they feel motivated with the activities they carry out, striving to improve and making commitments. The work carried out by the people participating in the study has allowed them to feel satisfied and selfsufficient because they live in an environment set up by themselves, since the activities they carry out demand responsibilities.

Older adults, when interacting with those around them, have acquired achievements in the past, sharing their experiences and living with someone represents for them a living sense of belonging, the presence in their lives of loved ones, make them have a continuous relationship and a task in company, is more easily found with the existence of common goods that are shared with those who are united, that sharing enriches friendship, help, love or participation in common tasks, helps to feel useful, understood, supported and benefited for the common task that gathers everyone and in a certain way protects them and has a vivid sense of the presence of so much less possibilities they have to succumb to their own failure and not have a meaning in their life in the company of others, because then they have a clear justification for their efforts.

The way in which older adults perceive life, the satisfaction or failure that they experience, is always a personal response that depends on the history of each one and the way in which they have assumed their lifestyle as they get older as has lived. ${ }^{13}$

(...)I think that my life is full of joys even though I am with this disease I live with the loved ones and they have always shown me love and above all understanding(...) AI (...)I have people around me who help me overcome this disease (...)RI

Older adults who value every day what they do in their family, their work, their community and in any other area, have a sense of achievements and a sense of deep satisfaction. This allows them to have a feeling of their own dignity and their own value, their status as a living being and their significance as a unique human being. These adults have carried out activities that allow them to enjoy themselves, feel motivated, feel good about themselves same.

\section{Demonstrating self-care practices}

Defined self-care, as all actions performed by the individual in order to maintain health, it could be observed that the elderly with diabetes mellitus has determined their own activities to obtain wellbeing originated by their individual experience through the process of their disease. ${ }^{14}$ The act of taking care of oneself is the responsibility of each human being for himself, of the cultivation of himself and for himself, emphasizing the importance of the individual's relationships with himself.. ${ }^{10}$

(...)I do not eat foods with sugar, I avoid many sweets (...) AI (...) I'm eating vegetables, little salt and fruit (...) OI (...) It is a disease and therefore requires that you take care of nothing else (...) JI Well nowadays I still know, take care of your diet, medical care constantly, be attending to make evaluations, change many lifestyle habits and even join insulin therapy (...) MI (...)Food is basic: antioxidants, fruits, vegetables, omega 3, vitamins and minerals, hygienic care (...) $R I$

It has been identified that older adults know the risk factors that worsen their disease and avoid both their medication and their selfcare. All claimed to take the medication despite sometimes forgetting, identifying that it is possibly the cause of their complications. Hygiene and staff and rest an important part of self-care is seen by the elderly as fundamental, which influences their health status, but often they cannot practice it due to complications they have had 
due to their illness. Self-care included all those practices that in the intercultural and social context, they have proven to be of great value to the population.

(...)I check my feet so they do not have wounds, I wash them with warm water so the nurse told me (...) RI (...) I take my medications that are several but I have to take them, but I lower or raise the glucose and they have to take me to the hospital (...) JI (..)When I bathe I get tired a lot and it takes longer for that reason I do not do it every day but if I change daily..." OI

For the care of their health, each person is responsible for the decisions that condition their situation, coinciding fully with the purpose of health promotion. However, when independence is affected by limitations such as amputation, blindness and as a consequence, deficit of self-care; in the Theory of self-care deficit describes and explains the causes that can cause this deficit. Individuals subject to limitations because of their health or relationships with it, cannot assume self-care or dependent care. Determines when and why the intervention of relatives, friends or the nurse is needed.

(...)Before I went to the market, to my things now my daughter does them, she even has to help me go to the bathroom(...) VI

When they suffer from a chronic illness they realize that they are in a stage of inability to learn new ways of managing their health and to live new experiences such as self-care of air conservation, water, elimination, activity and rest, solitude and social interaction, prevention of risks and interaction of human activity. promote the necessary conditions for life and maturation, prevent the appearance of adverse conditions or mitigate the effects of such situations, at different moments of the evolutionary process or the development of the human being in the adult and old age, that arise or are linked to the health states.

Self-care is then a practice that involves all stages of growth in which the person must work daily to achieve a harmonious and balanced development. The nurse acts when the individual, for whatever reason, cannot self-care. The nursing assistance methods that D. Orem proposes, are based on the nurse's help and/ or substitution relationship to the patient, and are: Acting in place of the person, helping or guiding the person helped, Supporting physics and psychologically to the person helped, promote an environment favorable to personal development, and teach the person who helps. ${ }^{15}$

\section{Perceiving death near}

Having understood that old age is natural, the person has a lot of experience, that presents physical wear and disease such as diabetes mellitus, it would seem that the elderly is prepared to accept death and have them reflect and prepare for it, accept naturally, and understand that you can look back and contemplate life with satisfaction or dissatisfaction according to your chores and lifestyle.

Death and pain are mysteries in one, together or separately, are offered to the human being from the first glimmers of consciousness. At first sight, death is a reality that comes to us violently: even the most tranquil, foreseeable and assumed death visits us with a crudity that is impossible to perceive as a free choice.

(...)To be old is to reach the end and it is natural, and God willing, there is to accept it and take it well (...) MI

According to the review, the author (41) confirms this with the following expression: "Old age is (already) death, social and socioeconomic death for those who have lost their prestige and productive capacity, and also for the most needy ..."
These contextual aspects succinctly described are only some of those that provoke the denial of death in the contemporary world, but there is still another element that is perhaps the one that has had the most impact in recent times on culture, idiosyncrasy and worldview and that has markedly affected the tendency to deny death and the human being, a situation that older adults perceive.

(...)Know that, at some point, I can leave; and it is not that he is fleeing; on the contrary, it is what gives you the ability to keep in mind (...) $J I$

Death is an existential process and that this process can give meaning to life and, therefore, to death itself loss and grief are potential findings while real losses "(and when someone is allowed)" the experience of being lost gives him the ability to find out how to get out of that situation. "But certainly is not considering the beauty of this moment of life that is fraught with fears and anguish, rather what is posed is the need to make this experience a creative opportunity for life, since a person's growth is linked to their ability to constructively manage the loss of life. ${ }^{16}$

The disease exposes the superficiality with which we often live engulfed in the thousand and one occupations of life. It can be a call to give depth to life,

(...)Well, sickness is what mortifies one, every day I ask God to help me, sir, if I know that one day I have to leave. (...) UI

The process of dying can become, with the pertinent accompaniment, an important experience for those people who are willing to face it. Because before the nearness of death, many questions are valued in a new and profound way. As hairstyle says: ${ }^{17}$ it is important to clarify two issues: One is that what is being considered here is the search for meaning in suffering and not necessarily the meaning of it. To do so would be closing roads and trying to make sense of what is presented, precisely as the meaningless absurdity of existence. Secondly, we must realize that the concept "sense" refers to two different and interrelated issues: the search for meaning, or the ultimate direction of life.

In the statements made, this word is used in the interesting combination of both notions. We can summarize what has been said so far by saying that "the moment of the end determines the value and meaning of a whole life, and this is of the utmost importance."

We must not ignore the fact that to find in death a possibility of existential growth it will be necessary, first, to overcome several phases that take place in that process and that every person should know so that the accompaniment and consolation action is more appropriate and relevant.

(...)Nothing can be done now, it is our time we come to the end of our lives (...)MI (...)I have not even thought about it, it must be very hard to have that problem ... He laughs (...)AI

It is precisely in that perspective that is shortened by the time available to the person, regardless of whether he or she is ready to die or not, that it must be understood that: "it is essential to our existence to have a reason to live. In other words: it is essential that life has a meaning.

When it does not, its degradation begins and the empire of death is affirmed in us. "It must be reiterated that death and suffering are not something apart from life, in fact they are daily events that some can uplift and others destroy. If these processes were experienced in depth, instead of being denied and repressed, undoubtedly the possibilities of humanization would be deeper, which is why, according to 
reference, ${ }^{18}$ it raises the possibility of extracting a creative sense of death, a meaning that makes it possible to "turn your life around" more complete, richer. That opportunity is lost for those who turn their backs on grief or brokenness and do not want to feel it. By refusing this creative opportunity, others are also denied. ${ }^{13}$

\section{Final considerations}

Older adults, when they are sick, lose their sense of life because they lack ends for their own lives, also of projects to reach them, in making the right decisions, above all they do not have clarity of their self-realization as a constant search of their cycle of life. lifetime, have a chronic illness that has them dependent on the family of their children and grandchildren, that makes sense in the most personal way, of spiritual growth and service of others, by sharing life, and sorrows perform self-care practices determined by their own activities to obtain well-being such as changes in many habits of life, hygienic care, food, medical care as assessment assistance, even being integrated into insulin therapy, in addition to knowing the risk factors that worsen your disease that prevent, they identify as the possible cause responsible for the appearance of their complications, omitting their medication, nevertheless they perceive near death, as a fact before which they must take an attitude of the life that they want to take, happened due to the illness, makes them reflect and recover the sense of life for the Faith.

\section{Acknowledgments}

Express our gratitude to the elderly for their acceptance as well as to the workers of the Hospital for the facilities granted and to each one of those who made it possible to carry out the study.

\section{Conflicts of interest}

The authors declare there is no conflicts of interest.

\section{References}

1. William D. Lineamientos generales de geriatría: Geriatría. 3rd ed. México DF: Manual Moderno; 1990:15-20.
2. Bowling A. La medida de la salud. En: Conceptualización de la función fisica. La salud y la calidad de vida. Barcelona, España: Masson; 1994:1-13.

3. Instituto Nacional de Estadistica e Informatica (INEI). 2010.

4. https://www.manole.com.br/envelhecimento-1-edicao/p

5. Teixeira MLM, Domenico SMRD, Mello NO, et al. Sentidos de vida: Um estudo transcultural entre gestores brasileiros e portugueses. Organizações \& Sociedade. 2006;13(38):15-30.

6. Manual "La Investigación Cualitativa". 1979.

7. https://www.casadellibro.com/libro-investigacion-cientifica-en-cienciasde-la-salud-6aa-ed/9789701026908/732682

8. Lüdcke M. El Estudio de Caso su Potencial en Educación. Brasil. Traducción por Lucia Aranda Moreno. 1986.

9. Ministerio de Salud. Análisis de la Situación de Salud Tumbes. Documento Técnico. 2012.

10. http://www.censida.salud.gob.mx/descargas/etica/Informe Belmont-11-2008.pdf

11. https://revistas.ucr.ac.cr/index.php/aie/article/view/9090

12. https://revistas.ucr.ac.cr/index.php/reflexiones/article/view/10970

13. Collière MF. Promover la vida. Madrid: McGraw-Hill-Interamericana; 1993:385.

14. Frankl, Viktor Emil. Em busca de sentido: um psicólogo no campo de concentração. 23rd ed. São Leopoldo: Sinodal; 2006b:136.

15. http://www.scielo.br/pdf/reeusp/v42n3/v42n3a18.pdf

16. ht t p://www.s cie 1 o.br/s c i e 1 o.php? pid=S 0102 79722010000200009\&script=sci_abstract\&tlng $=$ pt

17. https://www.abebooks.com/DOLOR-MUERTE-HUMANA-DIGNABIOETICA-TEOLOGICA/30132614204/bd

18. http://periodicos.pucminas.br/index.php/horizonte/thesis/view/21 